\title{
(C) OPEN ACCESS \\ Life expectancy of different ethnic groups using death records linked to population census data for 4.62 million people in Scotland
}

\author{
Laurence Gruer, ${ }^{1}$ Geneviève Cézard, ${ }^{1}$ Esta Clark, ${ }^{2}$ Anne Douglas, ${ }^{1}$ Markus Steiner, ${ }^{3}$ \\ Andrew Millard, ${ }^{4}$ Duncan Buchanan, ${ }^{5}$ Srinivasa Vittal Katikireddi, ${ }^{6}$ Aziz Sheikh, ${ }^{1}$ \\ Raj Bhopal ${ }^{1}$
}

\begin{abstract}
- Additional material is published online only. To view please visit the journal online (http://dx.doi.org/10.1136/jech2016-207426).

${ }^{1}$ Usher Institute for Population Health Sciences and Informatics, University of Edinburgh, Edinburgh, UK ${ }^{2}$ Demographic Statistics, National Records of Scotland, Edinburgh, UK

${ }^{3}$ Department of Child Health, University of Aberdeen, Aberdeen, UK

${ }^{4}$ Public Health Science Directorate, NHS Health Scotland, Glasgow, UK ${ }^{5}$ Information Services, NHS National Services Scotland, Edinburgh, UK

${ }^{6} \mathrm{MRC} / \mathrm{CSO}$ Social and Public Health Sciences Unit, University of Glasgow, Glasgow, UK
\end{abstract}

\section{Correspondence to}

Professor Laurence Gruer, Usher Institute for Population Health Sciences and Informatics, University of Edinburgh, Teviot Place, Edinburgh EH8 9AG, UK; gruer.health@gmail.com

Received 24 February 2016 Revised 30 May 2016 Accepted 4 July 2016 Published Online First 29 July 2016

\section{ABSTRACT}

Background Few countries record the data needed to estimate life expectancy by ethnic group. Such information is helpful in assessing the extent of health inequality.

Method Life tables were created using 3 years of deaths (May 2001-April 2004) linked to Scottish 2001 Census data for 4.62 million individuals with selfreported ethnicity. We created 8 ethnic groups based on the census definitions, each with at least 5000 individuals and 40 deaths. Life expectancy at birth was calculated using the revised Chiang method.

Results The life expectancy of White Scottish males at birth was 74.7 years $(95 \% \mathrm{Cl} 74.6$ to 74.8$)$, similar to Mixed Background (73.0; 70.2 to 75.8) and White Irish (75.0; 74.0 to 75.9$)$, but shorter than Indian (80.9; 78.4 to 83.4$)$, Pakistani (79.3; 76.9 to 81.6), Chinese (79.0; 76.5 to 81.5), Other White British (78.9; 78.6 to 79.2) and Other White (77.2; 76.4 to 78.1). The life expectancy of White Scottish females was 79.4 years (79.3 to 79.5$)$, similar to mixed background $(79.3 ; 76.6$ to 82.0$)$, but shorter than Pakistani $(84.6 ; 82.0$ to 87.3), Chinese (83.4; 81.1 to 85.7), Indian (83.3; 80.7 to 85.9$)$, Other White British $(82.6 ; 82.3$ to 82.9$)$, other White $(82.0 ; 81.3$ to 82.8$)$ and White Irish $(81 ; 80.2$ to 81.8).

Conclusions Males and females in most of the larger ethnic minority groups in Scotland have longer life expectancies than the majority White Scottish population.

\section{INTRODUCTION}

Life expectancy is a useful measure of population health but rarely estimated for ethnic minorities due to lack of data. Among the few countries recording the ethnic group of the deceased, the USA, ${ }^{1}$ New Zealand ${ }^{2}$ and Australia ${ }^{3}$ showed substantial differences in life expectancy, usually favouring the ethnic majority. Country of birth is used as a proxy for ethnicity in some countries but misclassifies people who do not identify with the majority ethnic group in their country of birth. Examples include the increasing number of people born in the UK whose parents or grandparents were immigrants, or White British born in India who returned to the UK after Indian Independence. ${ }^{45}$

Morris et $a l^{6}$ recently estimated the life expectancy of White, Asian and Black groups in England and Wales. Lacking data on the ethnicity of individual deaths, they used age-specific and sex-specific mortality rates for all output areas in England and
Wales, deriving the proportion of the population in each of the three groups from the 2001 Census. They then created life tables modelling the effect on mortality rates of increasing proportions of the population being Asian or Black, adjusting for the effect of area deprivation. Rees $e t \mathrm{al}^{7}$ drew on evidence of a relationship between self-reported health and subsequent mortality. They estimated age-specific and sex-specific mortality rates for 16 ethnic groups using the 2001 Census, where self-reported limiting long-term illness and ethnicity are recorded. The resultant mortality rates were then used to develop life tables. They also used a geographical weighting model. All three methods have clear limitations which the authors acknowledged.

For this article, we aimed to calculate life expectancies for larger ethnic minorities using a data set linking individual records in the Scottish 2001 Census, which records self-reported ethnicity, with subsequent death records.

\section{METHODS}

Linkage, security and disclosure

The Scottish Health and Ethnicity Linkage Study (SHELS) successfully linked death records to the 2001 Census records of 4.62 million people, including their self-reported ethnicity. The methods have previously been described. ${ }^{8}$ Full ethical and other approvals for the linkage, data security and analyses were granted by the Scottish Multicentre Ethics Committee and the Privacy Advisory Committee of NHS National Services Scotland. The data sets were only made available to named researchers with appropriate clearance and training in a safe haven at National Records Scotland (NRS). All analyses and outputs followed the NRS Disclosure Control Guidance for SHELS and were cleared for release by its disclosure committee.

\section{Data and analysis}

As recommended by the Office for National Statistics, ${ }^{9}$ to provide enough deaths to calculate life expectancy by ethnicity and sex, we based our life tables on deaths in the 3 years after the Scottish Census 2001, from 1 May 2001 to 30 April 2004. Our base denominator of 4.62 million people was corrected downwards if an individual was known to have died or left the UK. As the cohort only included individuals who completed the Census, deaths of individuals born or entering the country 
after 1 May 2001 were not included. The 2001 census reported on 14 different ethnic groups. For life expectancy estimates of reasonable precision, we needed at least 5000 individuals and 40 deaths in every male or female ethnic group. We thus report on the eight ethnic groups using the Census definitions and fulfilling these criteria.

We used the revised Chiang method (Chiang II) to calculate life expectancy at birth by ethnic group and sex, with 95\% CIs. ${ }^{10}$ This is a robust method for calculating life expectancy estimates for geographical areas ${ }^{11}$ and specific populations. ${ }^{12}$ To create the life tables, populations and deaths were counted by ethnic group, sex and 5-year age bands (except for 0, 1-4 and $>85$ years). Following Eayres' recommendations, no substitutions were made for zero death counts in any cell. ${ }^{13}$

\section{RESULTS}

Table 1 shows the estimated life expectancies for males and females in each of the eight ethnic groups. In comparisons, only values where the $95 \%$ CIs do not overlap are reported as different, roughly equivalent to $\mathrm{p}<0.01$. $^{14}$ The life expectancy of White Scottish males at birth was 74.7 years, overlapping with Mixed Background (73.0) and White Irish (75.0) but shorter than Indian (80.9), Pakistani (79.3), Chinese (79.0), Other White British (78.9) and Other White (77.2).

The life expectancy of White Scottish females was 79.4, overlapping with Mixed Background (79.3) but shorter than Pakistani (84.6), Chinese (83.4), Indian (83.3), Other White British (82.6), Other White (82.0) and White Irish (81.0). Among males and females, the 95\% CIs for Other White British overlapped with those of Indians, Pakistanis, Chinese and Other Whites indicating they were broadly similar.

\section{DISCUSSION}

To the best of our knowledge, this is the first time that life expectancies of different ethnic groups have been calculated in a European country using individual death records linked to selfreported ethnicity. We found that most of the larger ethnic minority groups had longer life expectancies at birth than the White Scottish majority, with the central estimates being longer by $2.5-7.9$ years.

Our study's main strength is that it calculates the life expectancies of ethnic minorities using self-reported ethnicity rather than country of birth ${ }^{5}$ and the death records of individuals rather than indirect mortality estimates. ${ }^{6} 7$ It has some weaknesses. We were notified about only some of the individuals who moved to other parts of the UK and none of those who moved elsewhere. Discrepancies could thus occur if the deaths of departing members of ethnic minorities were disproportionately missed, but there is little evidence for this. ${ }^{15}$ The age of some older people born outside the UK may not have been accurately recorded. The numbers were too small in several ethnic groups to calculate life expectancy and in the four non-White groups to allow stratification for examining the effects of socioeconomic status or country of birth.

Our estimates of life expectancy were slightly higher than those published by NRS for 2000-2002, with the differences being greater for males. ${ }^{16}$ The NRS figures were based on whole population estimates and all deaths registered in Scotland. Our cohort only included those who completed the Census with their ethnicity and were linked to NHS data via a unique identifier. ${ }^{8}$ Those who did not complete the Census were more likely to be male and people living in socially disadvantaged areas, care homes and prisons, all associated with lower life expectancy, ${ }^{17}$ with a similar profile for those who could not be linked.

Morris et $a l^{6}$ found that in England and Wales, overall Asian and White life expectancies were similar, but those of Blacks shorter. We had insufficient numbers in our study to assess the life expectancies of Africans or African-Caribbeans. Adjusting their models for socioeconomic circumstances increased the life expectancy estimates for Asians and Blacks, reflecting the higher average levels of disadvantage experienced by these groups in England and Wales. However, the situation in Scotland appears more complex. We know from other analyses that the socioeconomic profiles of the Asian ethnic minorities in Scotland vary according to the specific ethnic group and the socioeconomic measures used (see online supplementary table). In a paper on gastrointestinal disease in this cohort, 'ethnic variations were mostly not much altered by socioeconomic or country of birth adjustment'. ${ }^{18}$ We think that if we had been able to adjust for socioeconomic status, it would have been unlikely to alter greatly the differences in life expectancy between the ethnic groups.

Our results suggest that, among people living in Scotland in 2001, the three ethnic minorities of Asian origin, and Whites with other origins except Ireland, could have expected to live

Table 1 Life expectancy at birth, by sex and ethnic group in Scotland

\begin{tabular}{|c|c|c|c|c|c|c|c|c|c|c|}
\hline & \multicolumn{5}{|l|}{ Males } & \multicolumn{5}{|c|}{ Females } \\
\hline & $\begin{array}{l}\text { Total } \\
\text { deaths }\end{array}$ & $\begin{array}{l}\text { Total linked } \\
\text { census } 2001 \\
\text { population }\end{array}$ & $\begin{array}{l}\text { Expectation of } \\
\text { life at birth }\end{array}$ & $\begin{array}{l}\text { Lower } \\
95 \% \mathrm{Cl}\end{array}$ & $\begin{array}{l}\text { Upper } \\
95 \% \mathrm{Cl}\end{array}$ & $\begin{array}{l}\text { Total } \\
\text { deaths }\end{array}$ & $\begin{array}{l}\text { Total linked } \\
\text { census } 2001 \\
\text { population }\end{array}$ & $\begin{array}{l}\text { Expectation of } \\
\text { life at birth }\end{array}$ & $\begin{array}{l}\text { Lower } \\
95 \% \mathrm{CI}\end{array}$ & $\begin{array}{l}\text { Upper } \\
95 \% \mathrm{Cl}\end{array}$ \\
\hline \multicolumn{11}{|l|}{ Scotland } \\
\hline White Scottish & 65115 & 1949485 & 74.7 & 74.6 & 74.8 & 73875 & 2138645 & 79.4 & 79.3 & 79.5 \\
\hline $\begin{array}{l}\text { Other White } \\
\text { British }\end{array}$ & 4455 & 160235 & 78.9 & 78.6 & 79.2 & 4840 & 174750 & 82.6 & 82.3 & 82.9 \\
\hline White Irish & 965 & 20340 & 75.0 & 74.0 & 75.9 & 990 & 23160 & 81.0 & 80.2 & 81.8 \\
\hline Other White & 800 & 29945 & 77.2 & 76.4 & 78.1 & 675 & 35710 & 82.0 & 81.3 & 82.8 \\
\hline $\begin{array}{l}\text { Any Mixed } \\
\text { Background }\end{array}$ & 65 & 5310 & 73.0 & 70.2 & 75.8 & 60 & 5800 & 79.3 & 76.6 & 82.0 \\
\hline Indian & 55 & 6450 & 80.9 & 78.4 & 83.4 & 40 & 5890 & 83.3 & 80.7 & 85.9 \\
\hline Pakistani & 100 & 12930 & 79.3 & 76.9 & 81.6 & 50 & 12700 & 84.6 & 82.0 & 87.3 \\
\hline Chinese & 55 & 6530 & 79.0 & 76.5 & 81.5 & 45 & 6670 & 83.4 & 81.1 & 85.7 \\
\hline
\end{tabular}

Total deaths (3 years of deaths occurring between May 2001 and April 2004) and total Census 2001 linked numbers are rounded to the nearest five for disclosure reasons. 
several years longer on average than the White Scottish majority. The relatively poor health of the White Scots may explain much of these differences. Between 2003 and 2010, life expectancy for Scotland as a whole was 4-5 years shorter than that in many other Western European countries, although somewhat longer than in Eastern Europe. ${ }^{19}$ White Scots living in England have higher mortality rates than any other immigrant group except the Irish. ${ }^{20}$ The Asian groups in Scotland had similar life expectancies to the Other White British. Thus, if Asians in Scotland had instead settled in countries such as Switzerland, France or England, the comparison with the majority population might not look so favourable.

The causes of Scotland's poor health record are a matter of continuing debate. Much evidence points to material disadvantage and air pollution in early years and culturally mediated behaviours including smoking, drinking alcohol and unhealthy eating, which may be less prevalent in some ethnic minority groups. ${ }^{21}$ The possibility that people who migrate to another country, particularly over long distances, may be intrinsically healthier on average than those they leave behind (the healthy migrant effect) may also play a part. ${ }^{22}$ However, as these estimates are based on the age-specific death rates of the cohort in 2001-2004, they are not projections of future mortality experience. The extent to which ethnic minorities retain their distinctiveness or converge in health-related culture and behaviour towards the majority will influence future trends. ${ }^{23}$

Since the available Scottish death records for the first decade of the 21st century did not include the ethnicity of the deceased, these analyses were only possible because death records were linked to the 2001 Census where ethnicity was recorded. A linked cohort based on the 2011 Census is planned, providing an opportunity for updating in due course. Since 2012, the ethnicity of the deceased is requested as part of the death registration process in Scotland, to the best of our knowledge, uniquely in Europe. ${ }^{24}$ Provided that refusal rates are not disproportionately high in certain ethnic groups, this should soon allow life expectancies to be compared on an ongoing basis.

In conclusion, linking death records to a population census recording self-reported ethnicity provides the basis for

\section{What is already known on this subject}

The life expectancy of different ethnic groups in a defined population has rarely been calculated due to a lack of suitable data. Where it has, substantial differences between groups have often been found, typically in favour of the ethnic majority.

\section{What this study adds}

- Linking the 2001 Census, which recorded ethnicity, to subsequent death records provided enough data to estimate life expectancy for eight ethnic groups in Scotland.

- Most of the larger ethnic minority groups had longer life expectancies than the White Scottish majority. This may be due to the relatively poor health of the White Scottish population as much as to the good health of ethnic minorities. estimating the life expectancy of ethnic minorities. The longer life expectancies of the larger ethnic minorities in Scotland may reflect the poor average health of the White Scottish majority as much as the good health of minority groups. This highlights the scope for continuing health improvement across the whole population.

\section{Twitter Follow Srinivasa Katikireddi at @vkatikireddi}

Contributors LG was the lead writer. GC calculated the life expectancies with advice from EC. AD was the study research fellow. All authors helped interpret the data and critically revise successive drafts of the manuscript. RB is the principal investigator and guarantor of the study.

Funding This work was supported by the Scottish Chief Scientist's Office (grant number CZH/4/878) and Cancer Research UK (grant number C3743/A16594) with supplementary funding from NHS Health Scotland. NHS National Services Scotland and National Records of Scotland made 'in-house' contributions to the work. SVK is funded by a NRS Scottish Senior Clinical Fellowship (SCAF/15/02), the Medical Research Council (MC_UU_12017/13) and the Chief Scientist's Office (SPHSU13).

Competing interests None declared.

Ethics approval Scottish Multicentre Ethics Committee.

Provenance and peer review Not commissioned; externally peer reviewed.

Data sharing statement At present, unpublished data are not available from this study which uses data sets made available to the researchers under strict arrangements by agreement of National Records of Scotland and NHS National Services Scotland. A possible data sharing arrangement is currently under discussion.

Open Access This is an Open Access article distributed in accordance with the terms of the Creative Commons Attribution (CC BY 4.0) license, which permits others to distribute, remix, adapt and build upon this work, for commercial use, provided the original work is properly cited. See: http://creativecommons.org/ licenses/by/4.0/

\section{REFERENCES}

1 Arias E, Curtin LR, Wei R, et al. U.S. decennial life tables for 1999-2001, United States life tables. Natl Vital Stat Rep 2008;57:1-36.

2 Carter KN, Blakely T, Soeberg M. Trends in survival and life expectancy by ethnicity, income and smoking in New Zealand: 1980s to 2000s. N Z Med J

2010;123:13-24.

3 Phillips B, Morrell S, Taylor R, et al. A review of life expectancy and infant mortality estimations for Australian Aboriginal people. BMC Public Health 2014;14:1.

4 Ikram UZ, Mackenbach JP, Harding S, et al. All-cause and cause-specific mortality of different migrant populations in Europe. Eur J Epidemio/ Published Online First: 11 Sept 2015. doi: 10.1007/s10654-015-0083-9

5 Bhopal RS. Migration, ethnicity, race, and health in multicultural societies. Oxford University Press, 2013.

6 Morris M, Woods LM, Rachet B. A novel ecological methodology for constructing ethnic-majority life tables in the absence of individual ethnicity information. J Epidemiol Community Health 2015;69:361-7.

7 Rees PH, Wohland PN, Norman PD. The estimation of mortality for ethnic groups at local scale within the United Kingdom. Soc Sci Med 2009;69:1592-607.

8 Bhopal R, Fischbacher C, Povey C, et al. Cohort profile: Scottish Health and Ethnicity Linkage Study of 4.65 million people exploring ethnic variations in disease in Scotland. Int J Epidemiol 2011;40:1168-75.

9 Toson B, Baker A. Life expectancy at birth: methodological options for small populations. London: Office for National Statistics, 2003.

10 Chiang CL. The life table and its applications. Malabar (FL): R.E. Krieger, 1984.

11 Terashima M, Read GJ, Andreou P. What type of rural? Assessing the variations in life expectancy at birth at small area-level for a small population province using classes of locally defined settlement types. BMC Public Health 2014;14:162.

12 Chang CK, Hayes RD, Perera G, et al. Life expectancy at birth for people with serious mental illness and other major disorders from a secondary mental health care case register in London. PLoS One 2011;6:e19590.

13 Eayres D, Williams ES. Evaluation of methodologies for small area life expectancy estimation. J Epidemiol Community Health 2004;58:243-9.

14 Cumming $G$. Inference by eye: reading the overlap of independent confidence intervals. Stat Med 2009;28:205-20.

15 Norredam $\mathrm{M}$, Hansen $\mathrm{OH}$, Petersen $\mathrm{JH}$, et al. Remigration of migrants with severe disease: myth or reality?-a register-based cohort study. Eur J Public Health 2015;25:84-9.

16 National Records of Scotland. Life expectancy for administrative areas within Scotland 2010-2012 including revised estimates for 2000-2002 to 2008-2010. Edinburgh: National Records of Scotland, 2014. 
17 National Records of Scotland. Scotland's Census 2011. Estimation and adjustment strategy. http://www.scotlandscensus.gov.uk/documents/methodology/ census-est-adjust-strategy-nov2012.pdf

18 Bhopal RS, Cezard G, Bansal N, et al. Ethnic variations in five lower gastrointestinal diseases: Scottish Health and Ethnicity Linkage Study. BMJ Open 2014;4:e006120.

19 World Health Organisation Europe and Scottish Public Health Observatory. Scotland and European Health for all database 2012. http://www.scotpho.org.uk/ HFA2012I

20 Wallace M, Kulu H. Mortality among immigrants in England and Wales by major causes of death, 1971-2012: a longitudinal analysis of register-based data. Soc SC Med 2015;147:209-21.
21 Gruer L, Hart CL, Watt GC. After 50 years and 200 papers, what can the Midspan cohort studies tell us about our mortality? Public Health Published Online First: 5 Aug 2015. doi:10.1016/j.puhe.2015.06.017

22 Hajat A, Blakely T, Dayal S, et al. Do New Zealand's immigrants have a mortality advantage? Evidence from the New Zealand Census-Mortality Study. Ethn Health 2010;15:531-47

23 Lee $\mathrm{S}, \mathrm{O}^{\prime} \mathrm{Neill}$ AH, Ihara ES, et al. Change in self-reported health status among immigrants in the United States: associations with measures of acculturation. PLoS One 2013;8:e76494.

24 Christie B. Scotland introduces record of ethnicity on death certificates. BMJ 2012;344:e475. 